US Army Corps of Engineers $s_{\circledast}$

Engineer Research and

Development Center

DoD High Performance Computing Modernization Program (HPCMP)

\title{
Assessment of Workforce Systems Preferences/Skills Based on Employment Domain
}

Raed Jaradat, Erin Stirgus, Simon R. Goerger,

Randy K. Buchanan, Niamat Ullah Ibne Hossain, Junfeng Ma,

and Reuben Burch 
The U.S. Army Engineer Research and Development Center (ERDC) solves the nation's toughest engineering and environmental challenges. ERDC develops innovative solutions in civil and military engineering, geospatial sciences, water resources, and environmental sciences for the Army, the Department of Defense, civilian agencies, and our nation's public good. Find out more at www.erdc.usace.army.mil.

To search for other technical reports published by ERDC, visit the ERDC online library at https://erdclibrary.on.worldcat.org/discovery. 


\section{Assessment of Workforce Systems Preferences/Skills Based on Employment Domain}

Simon R. Goerger and Randy K. Buchanan

Information Technology Laboratory

US . Army Engineer Research and Development Center

3909 Halls Ferry Road

Vicksburg, MS 39180

Raed Jaradat, Erin Stirgus, Niamat Ullah Ibne Hossain, Junfeng Ma, and Reuben Burch

Department of Industrial and Systems Engineering

Mississippi State University

75 B. S. Hood Road

Starkville, MS 39762

Final report

Approved for public release; distribution is unlimited.

Prepared for DoD US Army Corps of Engineers

Washington, DC 20314

Under Program Element 0603461A, Task Number 01, Project Number DW5 


\section{Preface}

This study was conducted for the US Army Corps of Engineers (USACE), under Program Element 0603461A, Task Number 01, and Project Number DW5, for the DoD High Performance Computing Modernization Program (HPCMP). The technical monitors were Dr. Simon R. Groeger and Dr. Randy K. Buchanan.

The work was performed by the Institute for Systems Engineering Research (ISER) Branch, Computational Science and Engineering Division of the Engineer Research and Development Center, Information Technology Laboratory (ERDC-ITL). At the time of publication of this Miscellaneous Paper, Dr. Simon R. Goerger was ITL ISER Director; Dr. Jerrell R. Ballard Jr. was ITL Computational Science and Engineering Division Chief. The associated Technical Director was Dr. Robert Wallace. The Deputy Director of ERDC-ITL was Ms. Patti S. Duett and the Director was Dr. David A. Horner.

This paper was originally published online in the Engineering Management Journal 32(1) on November 8, 2019. Project funding was under Army RDTE.

The Commander of ERDC was COL Teresa A. Schlosser and the Director was Dr. David W. Pittman.

DISCLAIMER: The contents of this report are not to be used for advertising, publication, or promotional purposes. Citation of trade names does not constitute an official endorsement or approval of the use of such commercial products. All product names and trademarks cited are the property of their respective owners. The findings of this report are not to be construed as an official Department of the Army position unless so designated by other authorized documents. 


\section{Assessment of Workforce Systems Preferences/Skills Based on Employment Domain}

\begin{abstract}
Given the growing demand for a workforce with an understanding of system of systems, there is a need to assess an individual's systems thinking skills. This research was undertaken to address this need by measuring an individual's inclination to work on complex system problems based on their systems thinking score. This article investigates the correlation between employment domains and an individual's systems thinking preferences/skills. Results of this research show that each employment domain is significantly different in their systems thinking preferences/skills profiles as well as significantly different in how the employment domains perceive change and their system's worldview.
\end{abstract}

\section{$\mathbf{T}$} he World Economic Forum (2016) reports complex problem-solving and holistic systems thinking are the most important skills needed by organizations exhibiting a high degree of complexity. The need for holistic thinking is outpacing other skills such as team management, emotional intelligence, negotiation, and cognitive flexibility (World Economic Forum, 2016). The Forum's assertion is supported by the increasing intricacies experienced in organizations concerned with the need to better address systems growing under complexity (Boardman \& Sauser, 2006). Ever-expanding systems architecture including the integration, merging, and upgrading of legacy systems to support the demand of new goals and products supports the claim that systems thinking (ST) skills are required (Bjelkemyr, Semere, \& Lindberg, 2009; Clegg \& Orme, 2012; Cook, 2001). Practitioners such as engineers, engineering managers, and decision makers must adjust to dealing with increasingly complex systems and the challenges they present. Practitioners supporting complex systems, specifically system of systems (SoS), face the 'new normal' of challenges marked by increasing levels of uncertainty, ambiguity, emergence, complexity, interdependence, and integration as defined in Exhibit 1 (DeLaurentis, 2005; Gorod, Sauser, \& Boardman, 2008; Jaradat, Keating, \& Bradley, 2018; Sauser \& Boardman, 2008).

In this study, long-term employment positions are evaluated because we believe long-term employees' system skills are more likely to impact an organization compared to employees in short-term positions. Furthermore, when considering an organization's intellectual property, business, and cultural intelligence is typically cultivated and integrated into the systems thinking preferences/skills of the employees during longer-term employment (Wilensky, 1967).

Because complex systems face increasing emergency, evolutionary development, integration, interdependence, complexity, ambiguity, and uncertainty, specific challenges are posed for engineers who are expected to understand, manage, and solve problems within the complex system domain (see Exhibit 1). These engineers must systematically frame problems to effectively develop optimal solutions for their organization. Framing can become unclear in a rapidly changing environment (Mitrof, 1997). After the engineer has framed the problem, the next challenge is to determine what problem-solving approach to take. Because each problem can be different in this complex environment, there is no standard resolution and therefore no standard approach. The final challenge is for the engineers to understand and eventually make decisions that resolve issues within complex systems based on the culture of the work environment, relevant policies, and human dimensions.

The current literature identifies research gaps relevant to the challenges presented by complex systems, and these gaps should be addressed to enable successful management of these systems. One key gap is the limited research investigating the impact of employment domains on individual systems thinking preferences/skills. The review of relevant literature also shows that there are few systems thinking tools and techniques specifically designed for the system of systems (SoS) domain. Because current complex systems challenges can limit an organization's ability to engineer and manage socio-technical systems, it is essential to have a cadre of qualified individual contributors and engineering managers who can take a more holistic 'systemic' approach to deal with complex system problems. In this article, the correlation between individual systems preferences/skills and employment domain is investigated to determine which domain has employees who are better equipped to deal with complex system problems.

The set of challenges detailed in Exhibit 1 is not an exhaustive list; rather it is a focused list of typical challenges that engineers need to be aware of in order to minimize the negative impact these challenges pose to the successful management of complex systems. This study is designed to address the challenges of complex system problems by measuring an individual's ST preferences/skills and 
Exhibit 1. System of Systems Challenges

Challenge

Increasing Levels

Uncertainty Unexpected influences add uncertainty due to an incomplete knowledge of complex systems

Ambiguity Ambiguity exists when deciding how to take actions and make decisions due to the variable nature of a complex system

Emergence Unexpected behavior or patterns may emerge only after they occur due to challenges related to predicting complex systems

Complexity Complex systems are interrelated which creates difficulty in understanding, controlling, or explaining the system due to the influences of numerous different factors.

Interdependence Complex systems are marked by the interactions between various components of the system, leading to high levels of interrelationships and logical associations between systems.

Integration Different subsystems combine together to achieve goals requiring multiple levels of operational, managerial, and geographical dispersion.

then finding correlations between the employment domains and the individual's system preferences/skills.

An overview of ST and organizational complexities and current tools used to measure ST is presented next, followed by a discussion of the research design, the survey instrument used to collect the dataset, and the findings from this research. The results obtained from the study are then analyzed and interpreted. The article concludes with final thoughts, limitations, and future research.

\section{Review of the Literature}

Since this article investigates how complex problems are solved by practitioners, the review of relevant literature focuses on what a complex systems problem is, what instruments have been used to measure ST in a variety of capabilities, and why particular employment domains were chosen for this study.

\section{Complex Systems Problems}

Complexity and the derivative problems that come as a result of complexity are an emerging new reality for engineering managers. With these challenges (see Exhibit 1), many organizations tend to integrate their existing operations, processes, and systems to work together to achieve higher holistic goals that are beyond the capabilities of each individual system. This integration increases the interdependence of interactions and reduces the autonomy of single systems (Jamshidi, 2009; Maier, 2005). This is referred to as system of systems or SoS (Hossain \& Jaradat, 2018; Jaradat, Keating, \& Bradley, 2014; Keating \& Katina, 2011). The SoS problem domain is exacerbated by the limiting factors imposed by 'hard' technology-based solutions developed without due consideration for the 'soft' non-technology aspects of holistically developed solutions. SoS has been used in the military and other fields to solve complex problems that traditional system engineering practices were incapable of resolving (Owens, 1996; Skyttner, 2001).

In addition to the challenges driven by SoS, the employment domain in which the SoS challenge occurs can add further complexities. For example, the employment domain of an organization often determines the frequency of change. One example of this is a service-based company that works with insurance claims adhering to constant changes in both customer and government requirements is likely to be a more volatile SoS environment than a local municipality that has not experienced a budget increase or change in system software in a decade.

Several researchers have recognized the need to apply systems thinking perspective to successfully examine complex system problems (Checkland, 1999; Jackson, 2003; Katina, Keating, \& Jaradat, 2014; Keating, Padilla, \& Admas, 2008; Lawrence, Hossain, Nagahi, \& Jaradat, 2019). In essence, it is generally agreed that a more holistic perspective, rooted in higher-level ST, is necessary to more effectively understand and respond to complex systems. A need exists to identify a core group of qualified individuals who can successfully engage complex system problem domains with a commensurate level of skills required to navigate the technical and non-technical dimensions of these types of problems. A first step in identifying qualified individuals is to classify their self-identified preferences/skills as they relate to the complex system problem domain. With the challenges associated with complex systems, that is, SoS (Exhibit 1), designing and managing a complex system can be challenging; thereby increasing the importance for individuals who interact with a system to grasp the system's full scope and to view the system in its entirety. A wide breadth of knowledge about the system from technological intricacies to economic or cultural implications is needed for users and maintainers of these complex systems (Checkland, 1999; Flood \& Carson, 1993; Jackson, 2003).

\section{Employment Domain}

There is value in understanding the nuances in the different types of workplaces to better understand an individual's inclination toward managing complex system problems. Solving problems within a complex system requires employees who think systemically, and understanding ST is vital to understanding complex systems. However, before determining the need for ST preferences/skills training, the existing self-identification of ST preferences of individual practitioners dealing with complex systems must be measured. To measure ST, an instrument that captures the many aspects of ST preferences/skills within a complex organizational environment must be utilized and vetted against the work environment. The purpose of this study is to evaluate data collected from a published survey instrument developed by Jaradat et al. (2018) that measures ST preferences/skills to deal with complex problems based on employment domains. Through the review of the ST tools and techniques found in the relevant literature, three main gaps that are motivating this research and 
should be addressed to remedy the challenges presented by complex problems (Exhibit 1) were identified as follows:

- There are insufficient tools and techniques purposefully designed to deal with complex socio-technical problems in SoS. At best, some tools measure only one or two ST skills (Dolansky \& Moore, 2013; Hopper \& Stave, 2008; Plate, 2008). Many of the current tools are designed for specific domains such as education to test student ST skills (Camelia \& Ferris, 2018; Frank, 2002, 2010). These techniques, while they might satisfy a specific need, have not been designed or specifically structured to facilitate solutions to socio-technical problems. In addition, many of the current ST tools do not publish or show the accompanying evidence of validity and reliability. "There are over 200 instruments designed to measure any of a variety of attitudes toward science education, but most have been used only once and only a few show satisfactory statistical reliability or validity." (Camelia \& Ferris, 2018, p. 3).

- $\quad$ There is a need to build a survey instrument based on the domain of system theory. System theory encompasses the underlying theoretical foundation necessary to apply an ST paradigm to better understand complex problem domains. (Ackoff, 1995; Adams, Hester, Bradley, Meyers, \& Keating, 2014; Adams \& Keating, 2011; Checkland, 1999; Senge, 1990; Skyttner, 2001; Von Bertalanffy, 1968; Whitehead, Scherer, \& Smith, 2015).
- There is a lack of research focused on the relationship between employment preferences/skills and employment domains.

\section{Research Data and Methods}

Three employment domains, Industry/Business, Military, and Academic/Government, were analyzed to determine if either domain promotes more or less holistic thinkers. An overview of the survey instrument along with the instrument's validity and reliability is presented below, followed by a discussion of the study sample, the analysis performed, and the research findings.

\section{Data Collection}

A survey instrument was developed to determine the level of ST skills individuals need to successfully deal with complex systems problems (Jaradat, Campbell, \& Abutabenjeh, 2016). This ST preferences/skills survey instrument, which is based on the complex system attributes mentioned in Exhibit 1, was designed to measure an individual's predisposition for ST when dealing with problems of SoS complexity. These problems are encountered in many different fields such as healthcare, manufacturing, logistics, service, government, and military and tend to occur where multiple systems have been integrated due to acquisitions or architectural growth resulting from legacy technology.

The ST preferences/skills survey instrument uses a webbased survey to administer 39 binary questions examining the seven dimensions of ST (Exhibit 2). Participants choose their most preferred response from each dichotomous question. For example, one of the questions asks the participants: 'Are you

Exhibit 2. Systems Thinking Preferences/Skills Survey Instrument Dimensions (Jaradat et al., 2018)

\begin{tabular}{ll}
\hline Dimension & \multicolumn{1}{c}{ Less Systemic } \\
\hline Level of Complexity: Comfort with & $\begin{array}{l}\text { Simplicity (S): Avoid uncertainty, work on linear } \\
\text { multidimensional problems and }\end{array}$ \\
problems, prefer best solution, and prefer small-scale \\
limited system understanding & problems.
\end{tabular}

Level of Independence: Balance between local level autonomy versus system integration

\section{Level of Interaction:}

Interconnectedness in coordination and communication among multiple systems

\section{Level of Change: Comfort with rapidly shifting systems and situations}

Level of Uncertainty: Acceptance of unpredictable situations with limited control

Systems Worldview: Understanding system behavior at the whole versus part level

Level of Flexibility: Accommodation of change or modifications in systems or approach
Autonomy (A): Preserve local autonomy, tend more to independent decision and local performance level.

Isolation (N): Inclined to local interaction, follow detailed plan, prefer to work individually, enjoy working in small systems, and interested more in cause-effect solution.

Resistance to Change (V): Prefer taking few perspectives into consideration, over specify requirements, focus more on internal forces, like shortrange plans, tend to settle things, and work best in a stable environment.

Stability (T): Prepare detailed plans beforehand, focus on the details, uncomfortable with uncertainty, believe work environment is under control, and enjoy objectivity and technical problems.

Reductionism (R): Focus on particulars, prefer analyzing the parts for better performance.

Rigidity (D): Prefer not to change, like determined plan, not open to new ideas, motivated by routine.

\section{More Systemic}

Complexity (C): Expect uncertainty, work on multidimensional problems, prefer a working solution, and explore the surrounding environment.

Integration (G): Preserve global integration, tend more to dependent decision and global performance.

\section{Interconnectivity (I):}

Inclined to global interactions, follow general plan, work within a team, and interested less in identifiable cause-effect relationships

Tolerant of Change (Y): Prefer taking multiple perspectives into consideration, underspecify requirements, focus more on external forces, like longrange plans, keep options open, and work best in changing environment.

Emergence (E): React to situations as they occur, focus on the whole, comfortable with uncertainty, believe work environment is difficult to control, enjoy subjectivity and non-technical problems.

Holism (H): Focus on the whole, interested more in the big picture, interested in concepts and abstract meaning of ideas.

Flexibility (F): Accommodating to change, like flexible plan, open to new ideas, and unmotivated by routine. 
most comfortable developing (a) a detailed plan or (b) a general plan?' Responses are used to calculate a score for each ST dimension. This dimension score is calculated as the proportion of questions in that dimension in which the participant chooses the more systemic answer. A dimension score above 0.50 would indicate that the person is more systemic along that dimension (see Exhibit 2). A dimension score below 0.50 indicates less systemic thinking. Finally, an overall ST score is calculated by averaging the seven-dimension scores for each participant.

Each ST question on the survey belongs to one of the seven ST preference dimensions. For each dimension, the scale extremity that was chosen most frequently in the binary question responses becomes the letter in the ST preferences/skills profile (see Exhibit 2), thus creating a 7-letter ST preferences/skills profile for each participant. Each participant is assigned a numerical score for each dimension based on the number of "more systemic" answers chosen for each dimension scale out of the total questions on each scale. Finally, the total ST preferences/skills score is calculated as an average of each dimension score (see Exhibit 3). As an example, an individual participant's responses may indicate an ST preferences/skills profile of SGIYTRD with scaled sub-scores and an overall score as shown in Exhibit 3. Each individual's profile, dimension scores, and total scores are computed in the dataset. The profiles presented in this study are based on the aggregate score in each employment domain.

All dimensions in Exhibit 3 have the same weight based on the analysis obtained through the validation process described in the next section. Results show that, although these dimensions have the same level of importance in this study, the level can vary based on the degree of complexity in the system and the environment that must be engaged by practitioners. Thus, there are no good or bad ST preferences/skills profiles because it depends on the degree of complexity in the SoS environment. For example, a manufacturingbased company that works with $3 \mathrm{D}$ printing design must deal with the dynamic changes in both customer and government requirements. This means that the company probably needs to focus more on the level of flexibility dimension than the level of systems worldview dimension. In this example, an individual with an ST preferences/skills profile that exhibits an inclination to being more flexible in dynamic environments might be more suitable than one who prefers not to work in a dynamic environment. An individual who prefers not to work in a dynamic environment does not mean that he or she has a bad ST skills profile but instead has a profile that may be more suitable to another environment.

\section{Validity of the ST Preferences/Skills Survey Instrument}

The validity and reliability tests are conducted for two main reasons: (1) to test if the ST preferences/skills instrument measures what it is intended to measure, and (2) to justify that the survey instrument questions are designed to measure the seven dimensions found in Exhibit 2. These tests are necessary to ensure that the survey instrument can produce accurate findings based on individuals' ST preferences/skills in the targeted employment domains.

To address the first gap in the literature, we present the advanced validity and reliability tests of the ST preferences/skills survey instrument (see Exhibit 4). Prior to deploying the survey instrument, several validity and reliability tests were performed over the course of 3 years to ensure the survey instrument measures what it is supposed to measure - individuals' ST preferences/ skills. To test the utility and check the validity of the survey instrument, Exploratory Factor Analysis (EFA), Confirmatory Factor Analysis (CFA), and modeling structure were performed. In addition, the construct validity, discriminant validity, and face validity of the survey instrument were obtained. Construct validity examines the relationships between the factors (constructs) and "refers to an examination of a measure of an attribute (or construct) that is not operationally defined or measured directly" (Cronbach \& Meehl, 1955, p.281). Model fit indices are used to achieve construct validity in CFA. There are four categories of model fit indices; namely Absolute Fit, Incremental Fit, Parsimonious Fit, and Non-Centrality-based Indices. The use of at least one fitness index from each model fit category is recommended by Hair, Black, Babin, Anderson, and Tatham (2010).

Exhibit 4 shows the results obtained for Absolute Fit, Incremental Fit, Parsimonious Fit, and Non-centrality-based Indices and indicate the model obtained has an excellent fit. All thresholds and literature support for these fit categories are also shown in Exhibit 4. Modification Indices (MI) indicate the item's redundancy through a discrepancy measure. Correlation coefficients are another indicator of discriminant validity as correlations higher than 0.85 would suggest that factors in each model are measuring the same things. In this research, four factors were obtained and these factors measure the seven dimensions through the 39 questions. We found that there are no correlations larger than 0.85 , and these factors can be thought of as independent with the same level of importance (weight).

\section{Reliability of the ST Preference/Skills Survey Instrument}

Reliability is the degree of consistency of an instrument. An instrument is deemed reliable if it always yields an identical score

Exhibit 3. Sample Dimension Score Calculation for an Individual Respondent

\begin{tabular}{|c|c|c|c|c|}
\hline Dimension & Number of ST Skills Questions & More Systemic Responses & Profile Designation & Dimension Score \\
\hline Level of complexity & 6 & 2 & $\mathrm{~S}$ & 33 \\
\hline Level of independence & 5 & 4 & G & 80 \\
\hline Level of interaction & 6 & 5 & 1 & 83 \\
\hline Level of change & 6 & 6 & Y & 100 \\
\hline Level of uncertainty & 6 & 2 & $\mathrm{~T}$ & 33 \\
\hline Systems worldview & 5 & 2 & $\mathrm{R}$ & 40 \\
\hline Level of flexibility & 5 & 1 & $\mathrm{D}$ & 20 \\
\hline Overall & & & SGIYTRD & 56 \\
\hline
\end{tabular}


Exhibit 4. Summary of Validation and Reliability Tests

\begin{tabular}{lllll}
\hline Instrument Model & & Index & Final Model (Instrument) & Threshold Literature \\
\hline Absolute fit & GFI & Goodness-of-fit index & 0.89 & 0.012 \\
& RMR & Root Mean Square Residual & 0.886 & SRI $>0.80$ is good \\
Incremental fit & TLI & Tucker-Lewis index & 0.811 & 0.030 \\
Parsimonious fit & PCFI & Parsimony corrected Comparative Fit Index & TLI $>0.90$ \\
Non-centrality-based Indices & RMSEA & Root Mean Square of Error Approximation & RMSEA $<0.05$ \\
& RMSEA 90\% Cl & RMSEA 90\% confidence interval & 0.5 \\
& CFI & Comparative Fit Index & CFI $>0.90$ \\
\hline
\end{tabular}

(Kerlinger \& Lee, 2000). The assessment for the reliability of the ST preferences/skills survey instrument was performed using Internal Consistency Reliability (ICR) and composite reliability (CR).

Internal Consistency Reliability shows how strong the instrument questions measure the respective construct together. In general, reliabilities in the 0.70 range are acceptable, and those over 0.80 are good (Sekaran, 2003). Cronbach's coefficient Alpha (ICR) results show promising results for the ST preferences/skills instrument with a Cronbach's Alpha close to 0.90. The CR shows the reliability and internal consistency of a latent factor. A value of CR > 0.6 is required in order to achieve composite reliability for a construct (Tseng, Dörnyei, \& Schmitt, 2006). Based on these results, the model with four factors has achieved composite reliability because all CR values of the four factors are in the higher range of 0.7. In sum, after gaining unidimensionality, construct validity, discriminant validity, and internal consistency reliability, the final version of the survey instrument with 39 questions meets the criterion of composite reliability. Therefore, the ST preferences/skills instrument and its applications are determined to be valid and reliable.

\section{Study Sample Size}

The population of interest for this study is systems engineers and engineering managers. An invitation email was sent to 290 individuals to participate in the study. The invitation included a web-link with instructions to take the survey, which most participants completed in 10-15 minutes. The participant pool was identified based on the degree of complexity (challenges) identified in Exhibit 1. Since the aim of the study is to compare between three domains, we targeted representative groups in each domain (e.g. Military domain). Phone interviews were conducted to determine the participated group.

The study sample of 290 participants was $80 \%$ male and $20 \%$ female. After filtering the dataset based on incomplete survey results, 273 were included in the analysis. Participants reported working for one of the three employment domains: Academic/ Government $(n=100)$, Industry/Business $(n=117)$, or Military $(\mathrm{n}=56)$. All study participants hold systems engineering and/or engineering management positions. Among the 290 participants, $17 \%$ have 11-15 years of work experience, 3\% have 16-20 years, and $80 \%$ have 21 or more years of experience in the field of systems engineering and engineering management. Thirty-two percent of the participants hold bachelor's degrees, 55\% master's degrees, and $13 \%$ doctoral degrees. Twenty-five U.S. organizations/institutions participated in the study, and all have a systems engineering department/division. Other demographic factors collected during the study include family size, field of highest degree, and current occupation. The sample size was large enough to minimize the measurement design errors.

\section{Study Findings}

In order to find patterns and guide interpretation of results, the survey results have been compiled for each employment domain. The ST preferences/skills survey instrument determines the relative level of ST preferences/skills and inclination for dealing with complex system problems for the three domains in the study. A summary of descriptive statistics for the seven dimensions of ST preferences/skills as well as an overall ST score is shown in Exhibit 5. The seven dimensions outlined in Exhibit 5 determine the aggregate level of participants from each domain type and indicate their predisposition in understanding complex problem. As Exhibit 5 indicates, Military and Industry domains scored higher than academic in the flexibility dimension.

Tukey-Kramer Honest Significant Difference (HSD) posthoc analyses were conducted to evaluate the differences between the employment domains (see Exhibit 6) and indicate significant differences exist between employment domains for two ST preferences/skills dimensions: Change and Systems Worldview. Regarding the Change dimension, participants from the Military group had significantly higher scores than the other two groups. Participant scores for the Systems Worldview dimension were significantly lower for the Academic/ Government participants than the other two groups. Regarding overall ST score, the Military domain was significantly higher than the Academic/Government domain.

Based on the results of the study we suggest several critical points for considerations related to: (1) understanding the developmental indications for increasing the capacity of the workforce to more effectively engage complexity and (2) considerations for potential complexity blindspots that appear to be prevalent in a particular domain.

The Military domain suggested an ST grouping preference profile that was dominated by a holistic (focus on whole first and parts secondary). However, there was also some residual reductionist (focus on parts first and wholes secondary). While it is beyond the present research to posit explanations as to why this exists, we can offer some implications. First, for situations that are highly complex (large number of variables, richly interconnections among elements, dynamic nature, and high levels of uncertainty), care must be taken to allocate systems thinking resources commensurate to the complexity demands of the task/situation. Second, where there are elements of a task/ 


\section{Systems Thinking (ST) Categories}

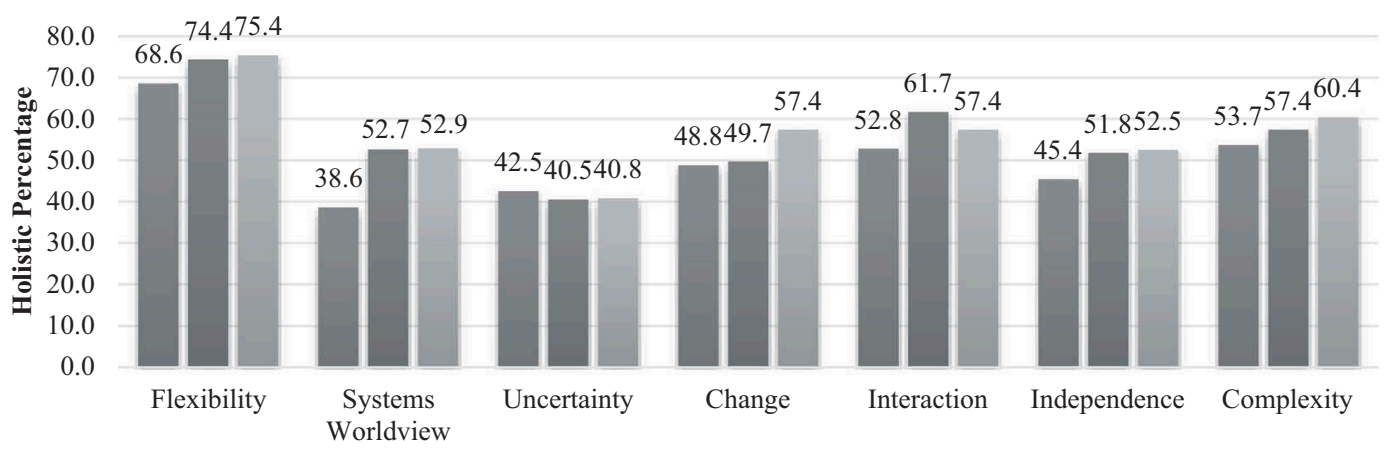

ST Categories

- Academic/Government $=100 \quad$ Industry/Business $-117 \quad$ Military -56

Exhibit 6. Employment Domain Analysis

\begin{tabular}{|c|c|c|c|c|c|}
\hline & & Sum of Squares & Mean Square & $\mathrm{F}$ & Sig. \\
\hline Overall Score & Between Domains & .201 & .100 & 4.155 & .017 \\
\hline Complexity & Between Domains & .175 & .088 & 1.445 & .238 \\
\hline Independence & Between Domains & .280 & .140 & 2.075 & .128 \\
\hline Interaction & Between Domains & .422 & .211 & 2.719 & .068 \\
\hline Change & Between Domains & .299 & .149 & 4.214 & .016 \\
\hline Uncertainty & Between Domains & .024 & .012 & .223 & .800 \\
\hline Systems Worldview & Between Domains & 1.263 & .632 & 8.220 & .000 \\
\hline Flexibility & Between Domains & .238 & .119 & 1.869 & .156 \\
\hline Overall ST & Between Domains & .218 & .109 & 4.526 & .012 \\
\hline
\end{tabular}

situation that demand a more reductionist approach, care should be taken with respect to the assignment of personnel that have capabilities consistent with the task/situation demands. Third, having a mix of ST preferences/skills can offer a variety of perspectives on different situations, where each thinking preference might contribute to better formulation and engagement of the complex system problem domain. This indicates that every complex system problem can benefit from a range of systems thinking (holistic to reductionist).

The Academic/Government and Industry/Business domains suggest a more centrist position between holistic and reductionist. Lacking precise knowledge as to why this profile exists, there are possible implications. First, a more balanced ST profile suggests the existence of diverse systems thinking preferences/skills. While this is neither good nor bad, it may bring limitations related to the assignment of personnel to extremely complex system situations. This is particularly the case where higher-order systemic thinking is the dominant mode of thinking appropriate to the task/problem/situation. Second, a more balanced profile suggests that there is diversity in ST preferences/skills that is built into the domain type and may provide benefits by incorporation of multiple perspectives. Third, it was noted that the Academic/Government sample was more skewed to the reductionist perspective in several ST dimensions (Systems Worldview, Change, Uncertainty, and Independence). Thus, for tasks/problems/situations that require a more holistic perspective related to these four dimensions, caution should be exercised so as not to preclude a level of thinking congruent to that demanded.

There are several additional considerations suggested from the research. Among these we include: (1) development of appropriate ST preferences/skills should be approached based on the degree of complexity engagement required of an organizational entity, (2) while ST is generally considered an asset for individuals/organizations, it can create blind spots with respect to more stable task-oriented work where more reductionist thinking/approaches may offer greater compatibility, (3) the needs for ST preferences/skills can shift over time and adjustment based on situational changes, and (4) ST preferences/skills should be viewed not only intrinsically (capacity held within the organization/entity in focus) but also extrinsically (capacity necessary to engage external environment complexity demands). 


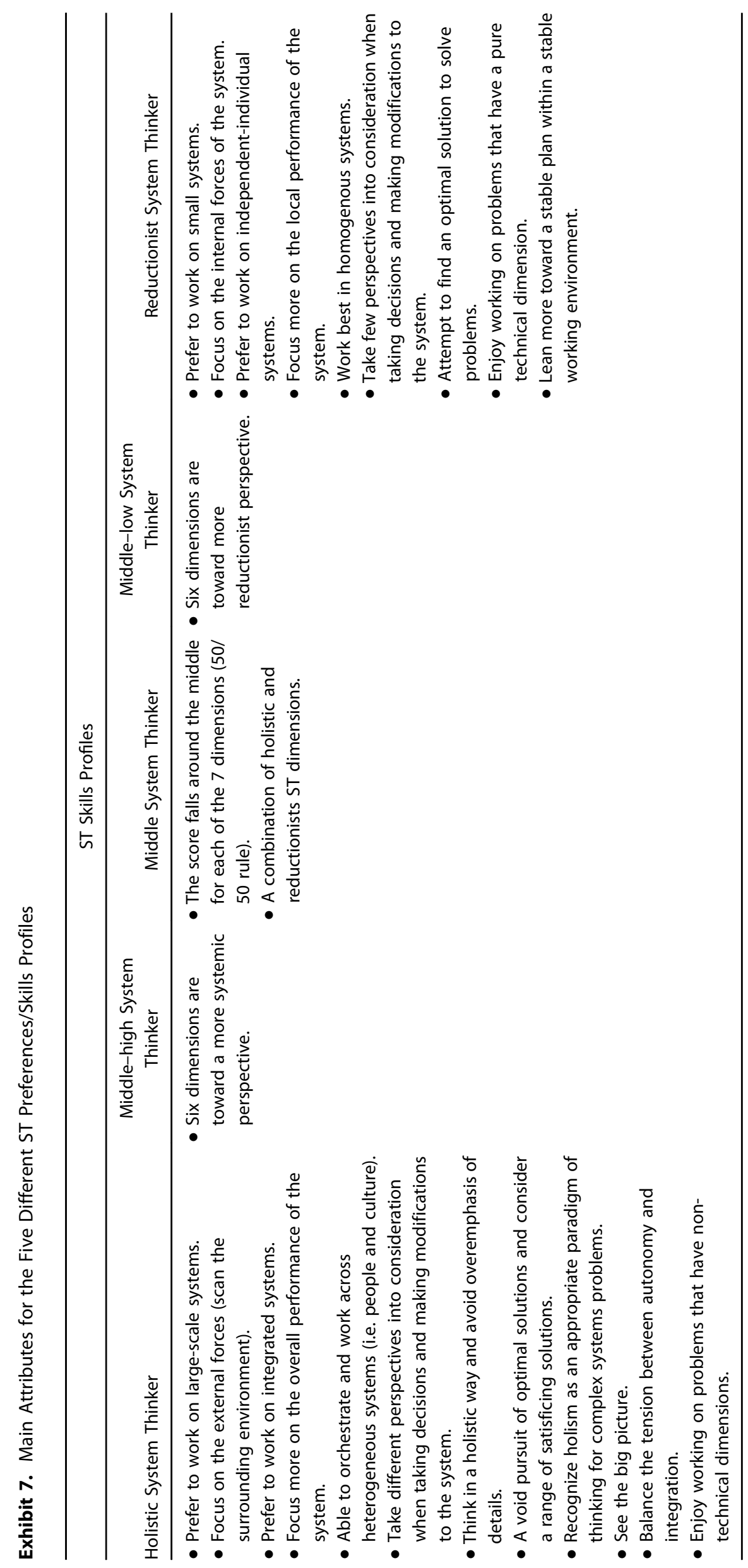




\section{Employment Domains Discussion}

Exhibit 7 shows the ST grouping preference profile that ranges from a purely holistic thinker to a purely reductionist thinker. Exhibits 2 and 8 are used to categorize the participant level of ST preferences/skills for each employment domain. The primary objectives of the discussion are to: (1) identify central themes of each domain related to ST preferences/skills and (2) suggest broad conclusions based on the study results.

\section{Participant ST Preferences/Skills Profile in Industry/Business Domain}

Based on the aggregate analysis obtained from the Industry/ Business domain, overall the participant ST preferences/skills profile indicates a systemic perspective that fits in the middle of the two extremes of holistic and reductionist being slightly more holistic than reductionist. Industry/Business domain participants lean toward working in complex systems but do not have a profile at the extreme of holism (Exhibit 7). Below are summarized points of ST preferences/skills profile generated for the Industry/Business domain:

The level of Complexity dimension, complexity vs. simplicity, describes the participants' inclination to work in complex system domains (Exhibit 2). The findings related to Industry/ Business participants show that they:

- Enjoy working more on problems that are moderately between not too simple and not too complex

- Prefer to work on problems that have more technical issues than human/social, organizational/managerial, and political components

- Prefer not to work on problems that integrate multiple systems

- Tend to accept optimal (the best) solutions as opposed to satisficing (good enough) solutions.

Therefore, with respect to Complexity, the Industry/Business domain participants display preference for dealing with more complex systems. This is indicative of a level of comfort in navigating the complexity faced by modern complex systems.

The level of Independence dimension, autonomy vs. integration, indicates the participants' comfort zone in dealing with the integration of multiple systems. The score for the Industry/ Business domain falls in the middle between autonomy and integrations. This means that Industry/Business participants:

- Lean more toward independent decisions (making the final decisions) in their systems instead of dependent decisions (working with others to make the final decisions)

- Focus more on local performance yet have some general interest in the overall SoS performance

- Focus less on other sub-systems (e.g. an asset management system within a larger manufacturing processing system) performance.

While there is a middle range between autonomy and integration, the propensity for independence and local performance could be of concern when challenges exist for the integration of multiple complex systems.

The level of Interaction dimension, isolation vs interconnectivity, describes the type of work environment the Industry/ Business participants prefer. Based on their scores, they:
- Desire for working on solving system problems with a team

- Prefer detailed work plans but can work and apply a flexible plan based on the problems

- Avoid working on problems that interact with other subsystems by focusing more on their local problems within a department level.

This particular dimension presents some interesting distinctions with respect to the preferences for the interaction of modern systems. With greater preference toward detailed plans, local system focus, and team emphasis, there is considerable potential for missing the challenges related to interaction, which may be strong among team members but limited with a preference for local focus.

The level of Change dimension, resistance to change vs. tolerant to change, deals with the participants' inclination to make changes in complex problems. Participants within the Industry/Business domain are equally between resistance and tolerance to change. Their score shows that they:

- Prefer to work in more stable work environments versus dynamic and changing environments

- Are apt to take few viewpoints into consideration before making a change or adjustment in the system

- Focus more on internal (local) forces of the system (e.g. a lack of concern for what competitors might be changing in their systems and not adjusting the system for the surrounding environment).

The Change dimension identifies challenges for the Industry/Business domain. In particular, the propensity for stable work environments, limited viewpoints, and local focus has the potential to provide too narrow of a perspective for effectively dealing with complex systems.

The level of Uncertainty dimension, stability vs. emergence, deals with the participants' preference in making decisions under uncertainty. Based on their scores, Industry/Business domain participants:

- Prefer working on technical problems and not technicalsocial problems

- Focus more on the details of the problem

- Lean toward working in environments that are controllable and static

- Are not comfortable in dealing with uncertainty or any emergent behavior that might disrupt the system at any time.

The Uncertainty dimension suggests that highly volatile environments subject to increased levels of emergence may present difficulties for enterprises in the Industry/Business domain. Effectively dealing with uncertainty is essential to working within increasingly complex SoS and their emergent issues.

The level of Systems Worldview dimension, reductionist vs. holism, describes the participants' predisposition in understanding system behavior as a whole versus as multiple parts. Their score identifies that they:

- Focus more on particulars in solving problems by analyzing the parts for a better performance.

- Focus more on the local performance of the system 
- $\quad$ Prefer the optimal solution to system problems

- Formulate a problem by identifying the cause-effect paradigm.

The Systems Worldview dimension suggests a leaning toward the reductionist perspective. In dealing with complex SoSs and their problems, a reductionist perspective is not a sufficient worldview. The responses from the reductionist worldview are incongruent with the complexity inherent in modern systems. The reductionist worldview presents particular difficulties in dealing with highly emergent, ambiguous, and uncertain conditions that dominate complex systems.

The level of Flexibility dimension, rigidity vs flexibility, deals with the participants' accommodation to change and making adjustments within the system. Their scores suggest that they:

- Are open to implementing new ideas in the system if needed (i.e. implementation of a new technology)

- $\quad$ Are motivated by change but not by routine work

- Are comfortable deviating from the detailed work plans in order to make adjustments in the system (e.g. accounting for changes in the external environment that may cause a change in scope from previous planned system modifications).

This is a bright spot for the Industry/Business domain. Flexibility implies that enterprises in this domain are well suited to make adjustments based on changing circumstances in systems. While this does not imply that the conditions requiring flexibility are desirable, it does imply that flexibility in response to changing conditions is a capability.

\section{Participant ST Preferences/Skills Profile in Military Domain}

We now shift focus to examine the Military domain and focus on the significant differences in the Military domain as compared to the Industry/Business domain. Based on the analysis of the Military domain, there are some similarities with the Industry/ Business domain as Military participants share highly comparable profiles in their levels of Complexity, Independence, Interaction, and Uncertainty (see Exhibit 5). However, there are significant differences between two of the dimensions. One dimension where a significant difference exists is the Level of Change $(p$-value $=0.016<.05)$ (Military $>$ Academia/Government; Military $>$ Industry) (see Exhibit 6). The results show that participants from the military: (1) are more comfortable working in a changing and dynamic environment, (2) focus more on the external forces such as the surrounding environment of the system, and (3) focus on obtaining a flexible system design.

In the Military domain, the participants' ST preferences/skills profiles lean toward a middle-high systemic perspective (see Exhibit 5). This profile indicates that these participants lean toward working in complex systems. However, the score is not high enough to definitively show military preferences for working in large SoS.

\section{Participant ST Preferences/Skills Profile in Academic/ Government Domain}

The results obtained from the Academic/Government domain contain similarities to both the Industry/Business and Military domains. For instance, Level of Complexity and Level of Independence are comparable across all three domains.

The largest differences between the Academic/Government domain (lowest scores) and the other domains are their levels of Change, Systems Worldview, and ST preferences/skills overall score (see Exhibit 5), which implies these participants:

- Are not comfortable working in a changing and dynamic environment

- Are not likely to consider multiple perspectives prior to making decisions

- Focus completely in particulars in solving problems by analyzing the parts for a better performance

- Focus on the local performance of the system

- Prefer the best solution to the system problems.

Based on participants' self-perception of their ST preferences/ skills, none of the domain participants were classified as Holistic System Thinkers (see Exhibit 7) which as stated previously corresponds to the workforce systems skills gap identified in the literature (Dagli \& Kilicay-Ergin, 2008; Trochim, Cabrera, Milstein, Gallagher, \& Leischow, 2006). Because of complex SoS problems, more holistic thinkers are needed in order to progressively solve the issues inherent in these ever-expanding technical environments (National Science Foundation, 2017), but no single domain had an aggregate participant score of purely holistic.

Based on participants' self-identified ST preferences, the closest sector to true holistic thinking was the Military domain participants who classified as Middle-High System Thinkers meaning that responses to six out of seven categories were that of a systemic preference (see Exhibit 7). Their more holistic view may stem from the fact that military personnel work in an environment which demands more awareness of and integration in larger-scale systems (Allison \& Cook, 1997; Cook, 2001; Dagli \& Kilicay-Ergin, 2008; Owens, 1996). They tend to be largely more flexible given their need to solve potentially life-critical issues using solutions that may not be as well-planned, as preferred. Because safety is a larger career concern in the military, an inherent awareness of what others in the system are doing establishes greater overall awareness.

The Industry/Business domain profile classified as Middle Systems Thinkers. Like the military, industry professionals must be able to resolve problems quickly using non-ideal solutions that get the job done. This is due to the tactical, day-today emergent needs often experienced in industrial environments where health and safety, environmental conditions, and customer scope creep often can quickly redirect focus. Given the study includes participants from multiple industry and business types, it is likely that the diversity between work skills is what led to a fairly average aggregate versus what data from a study between different industry work sectors might reveal.

The Academic/Government domain scores lowest in the Systems Worldview dimension, Change dimension, and overall ST score. Since governments are not known for making changes quickly, resistance to dynamic environments is expected. To understand more about this Middle Systems Thinkers profile, the researchers surveyed the literature in public administration and found that the results are consistent showing that a lack of incentives and motivations prevent innovation and change in the public sector. Wright and Meadows (2012) identified some traps that are related to public managers including policy resistance, drift to low performance, tragedy of the commons, and escalation (feedback loop). From an academic perspective, the result of this study agrees with past literature as well since an academic culture encourages the learning of concepts individually, thereby creating future workers who are not as skilled in complex, holistic thinking as required by 
the job domains that hire them (Foundation, 2017; Jackson, 2003; Kordova, Ribnikov, \& Frank, 2015; Sweeney and Sterman (2000); Trochim et al., 2006). The NSF emphasizes the need of advancing holistic engineering formation since the U.S market lacks holistic engineers (Foundation, 2017).

\section{Implications for Engineering Managers}

With the SoS challenges mentioned throughout the article, the world for engineering managers is becoming increasingly complex, emergent, evolutionary, and interconnected due to systems and their embedded subsystems. To meet the demands of these systems, it is necessary to expand current and future engineering managers' skillsets by encouraging an exploration of new outlooks and new ways of thinking to better understand and manage the technical and non-technical problems associated with complex systems. Below is a summary of the main implications of the research:

- Match ST preferences/skills and job requirements: Using the profiles compiled through the ST skills survey instrument used in this study, engineering managers can develop employee-job models that match employee preferences with the requirements of the job. Because the instrument measures an individual's self-identified ST skills/preferences, it can be used to determine their inclination for dealing with complex SoS problems (Exhibit 2). Matching employees to appropriate jobs will help avoid solving the wrong problem precisely (Mitroff, 1997).

- $\quad$ Form diverse research teams: Using the ST preferences/skills profiles will help engineering managers form diverse research teams to work on SoS. Depending on the mission, a team consisting of too many reductionist or too many holistic profiles might not lead to mission success. Being aware of the team profiles could lead to more efficient teamwork and more efficient problem-solving. It is somewhat naïve to think that the development of systems thinking preferences/skills is a one size fits all proposition. On the contrary, based on the current research, there are two primary implications for systems thinking development in the domains examined. First, the limitations identified for the domains can offer a prioritized set of systems thinking developmental knowledge. Thus, scarce developmental resources can be targeted to achieve the highest impact. Second, development can be focused across a broad spectrum of enterprise levels including individual, system, entity, or entire enterprise. This amplifies systems thinking preferences/skills by developing multiple levels simultaneously and permits more comprehensive development as opposed to a singular focus on the individual level exclusively.

- Setting realistic goals: The ST preferences/skills survey instrument can help engineering managers identify realistic goals and objectives that are compatible with the current ST preferences/skills profiles of their team. For example, in a situation where the goal is to integrate the fuel tank systems between three aircrafts for a specific mission, the engineering manager can assess if this is a realistic goal given the ST preferences/skills profiles of the individual contributors on his team. In this case, a fully vetted, integrated design would be a more realistic goal for holisticminded engineers than for reductionists.

- Proper training: Having the ST preferences/skills profiles would help engineering managers design more effective training programs and continuing education opportunities that would target the improvement of the ST preferences/ skills needed to successfully engage problems in complex systems domains. The profiles for each of the employment domains suggest areas that are potentially problematic for domain practitioners. Therefore, awareness of these areas can provide practitioners with knowledge of potential failure modes should they be left unaddressed. Experiencing failure modes related to the different deficient ST dimensions can potentially be precluded with vigilance in limiting their occurrence.

\section{Conclusions}

During this study, three employment domains were analyzed for their system skills based on literature identifying the need for more holistic thinking individuals within the workforce. A survey instrument for measuring ST preferences/skills derived from past research was designed to measure an individual's predisposition for ST when dealing with problems of system complexity. The survey instrument was utilized for assessing the employment domain participants on a scale measuring the two extremes from holistic thinker to reductionist thinker. To classify the ST preferences/skills profile for each domain, seven dimensions (Flexibility, System Worldview, Uncertainty, Change, Interaction, Independence, and Complexity) were evaluated based on participants' response (self-identification) to determine their possession of the necessary capabilities required for job skills supporting complex systems. Using participant data from each workforce sector and based on the ANOVA analysis (see Exhibit 6), each employment domain fell into an ST preferences/skills profile according to the participants' preferences for either holistic or reductionist views. The ST preferences/skills survey instrument used in this study highlights the gap previously identified that the current workforce may not possess the systems skills needed to solve the ever-evolving SoS problems experienced by all three domains.

\section{Study Limitations}

While this research evaluates the effectiveness of the ST preferences/skills survey instrument, there are limitations that can be resolved in future experiments. More participants will be evaluated in future studies ensuring that each domain has equal representation. Additional information about the types of industries and businesses will also be captured so that similar organizations can be grouped together to learn more about the differences existing between industries as opposed to combining all industry and business employees into a single group. Likewise, for government and academia, more participants and equal representation are needed to further examine potential differences in ST preferences/skills.

\section{Future Research}

There are additional directions that ST preferences/skills research can take. For example, demographic effects on ST characteristics such as educational background, gender, generational cohort, ethnicity, culture, family size, and country of origin could all prove to have some level of influence on holistic or reductionist perspectives. This would ultimately assist engineering managers to design better training programs improving ST preferences/skills based on demographics. Further investigating the type of work being performed and the skill type of the employees such as blue, gray, or white-collar 
job functions as well as the duration of time spent in those roles could influence ST characteristics. Personality assessment scores contrasted with the scores received from this ST preferences/skills survey instrument would also be valuable as such traits as introversion or extroversion, internal versus external locus of control, and general self- and social awareness may influence participant problem-solving preferences. On a much larger scale, ST preferences/ skills assessments could be performed on the different groups and divisions within a large organization to show the different levels of SoS complexity problem-solving skills across a management hierarchy. Simply put, there are several areas where having an ST instrument would be valuable in understanding the impact of a holistic versus reductionist workforce as problem-solving requirements become increasingly complex.

To help engineering managers provide more efficient responses and solutions to the complex system problem domains, an emphasis must be placed on two main elements, individual capacity and environmental demand. This study focused on the individual capacity to measure what profile individuals hold in complex system problem domains based on their ST preferences/skills. From a systems perspective, every organization has a unique environment with which it must contend to sustain performance. Future research is needed to focus on the development of instruments that examine the degree of complexity that exists in the environment of an organization. Further analysis of the results would enable engineering managers to examine the degree to which current and planned initiatives contribute to addressing the ST preferences/skills gaps identified by the profile of the participants.

\section{Acknowledgements}

The authors would like to thank Lesley Strawderman for her assistance with data analysis.

\section{References}

Ackoff, R. L. (1995). 'Whole-ing' the parts and righting the wrongs. Systems Research and Behavioral Science, 12(1), 43-46. doi:10.1002/sres.3850120107

Adams, K. M., Hester, P. T., Bradley, J. M., Meyers, T. J., \& Keating, C. B. (2014). Systems theory as the foundation for understanding systems. Systems Engineering, 17(1), 112123. doi: $10.1002 /$ sys. 21255

Adams, K. M., \& Keating, C. B. (2011). Overview of the systems of systems engineering methodology. International Journal of System of Systems Engineering, 2(2-3), 112-119. doi:10.1504/IJSSE.2011.040549

Bjelkemyr, M., Semere, D. T., \& Lindberg, B. (2009). Definition, classification, and methodological issues of system of systems. In M. Jamshidi (Ed.), System of systems engineering-Principles and applications. New York, NY: John Wiley \& Sons.

Boardman, J., \& Sauser, B. (2006). System of systems-the meaning of of. In System of Systems Engineering, 2006 IEEE/SMC International Conference on (pp. 6-pp). Los Angeles, CA: IEEE.

Camelia, F., \& Ferris, T. L. (2018). Validation studies of a questionnaire developed to measure students' engagement with systems thinking. IEEE Transactions on Systems, Man, and Cybernetics: Systems, 48(4), 574-585. doi:10.1109/ TSMC.2016.2607224
Checkland, P. (1999). Systems thinking, systems practice (2nd ed.). New York, NY: John Wiley \& Sons.

Clegg, B., \& Orme, R. (2012). Systems of systems: Pure, and applied to lean six sigma. In A. Gheorghe (Ed.), System of systems (pp. 57-76). InTech. doi:10.5772/1406

Cook, S. C., \& Allison, J. S. (1997). The new era in military systems thinking and practice. Report, Australian Centre for Test \& Evaluation, University of South Australia.

Cook, S. C. (2001). 'On the acquisition of systems of systems.' Presented at the INCOSE Annual Symposium, Melbourne, Australia.

Cronbach, L. J., \& Meehl, P. E. (1955). Construct validity in psychological tests. Psychological Bulletin, 52(4), 281. doi: $10.1037 / \mathrm{h} 0040957$

Dagli, C. H., \& Kilicay-Ergin, N. (2008). System of systems architecting. In M. Jamshidi (Ed.), System of systems engineering-innovation for the 21st century (pp. 77-100). New York, NY: John Wiley \& Sons.

DeLaurentis, D. (2005). Understanding transportation as a system-of-systems design problem. In 43rd AIAA Aerospace Sciences Meeting and Exhibit (Vol. 1). Blacksburg, VA: ARC.

Dolansky, M. A., \& Moore, S. M. (2013). Quality and safety education for nurses (QSEN): The key is systems thinking. OJIN: the Online Journal of Issues in Nursing, 18(3), 71-80.

Flood, R. L., \& Carson, E. R. (1993). Dealing with complexity: An introduction to the theory and application of systems science. New York, NY: Plenum Press.

NSF. (2017). Research initiation in engineering formation. Program Solicitation NSF, 17-514.

Frank, M. (2002). Characteristics of engineering systems thinkinga $3 \mathrm{D}$ approach for curriculum content. IEEE Transactions on Systems, Man, and Cybernetics, Part C (Applications and Reviews), 32(3), 203-214. doi:10.1109/TSMCC.2002.804450

Frank, M. (2010). Assessing the interest for systems engineering positions and other engineering positions' required capacity for engineering systems thinking (CEST). Systems Engineering, 13(2), 161-174.

Gorod, A., Sauser, B., \& Boardman, J. (2008). System-of-systems engineering management: A review of modern history and a path forward. IEEE Systems Journal, 2(4), 484499. doi:10.1109/JSYST.2008.2007163

Hair, J. F., Jr, Black, W. C., Babin, B. J., Anderson, R. E., \& Tatham, R. L. (2010). Multivariate data analysis (7th ed). Englewood Cliffs, NJ: Prentice Hall.

Hopper, M., \& Stave, K. A. (2008, July 20-24). Assessing the effectiveness of systems thinking interventions in the classroom. 26th International Conference of the System Dynamics Society, Athens, Greece.

Hossain, N. U. I., \& Jaradat, R. (2018). A synthesis of definitions of systems engineering. In Proceedings of the International Annual Conference of the American Society for Engineering Management. (pp. 1-10). Coeur d'Alene, Idaho: American Society for Engineering Management (ASEM).

Infographics, S. (March 09, 2016). Top 10 skills [Infographic]. The Future of Jobs: World Economic Forum. Retrieved from http://reports.weforum.org/future-of-jobs-2016/shareableinfographics/

Jackson, M. C. (2003). Systems thinking: Creative holism for managers (pp. 378). Chichester, NJ: Wiley.

Jamshidi, M. (2009). System of systems engineering - Principles and applications. New York, NY: John Wiley \& Sons. 
Jaradat, R., Campbell, S., \& Abutabenjeh, S. (2016). How to find systems thinkers? Proceeding of the 2016 American Society of Engineering Education (ASEE). New Orleans, LA: ASEE.

Jaradat, R. M., Keating, C. B., \& Bradley, J. M. (2014). A histogram analysis for system of systems. International Journal of System of Systems Engineering, 5(3), 193-227. doi:10.1504/IJSSE.2014.065750

Jaradat, R. M., Keating, C. B., \& Bradley, J. M. (2018). Individual capacity and organizational competency for systems thinking. IEEE Systems Journal, 12(2), 1203-1210. doi:10.1109/JSYST.2017.2652218

Katina, P. F., Keating, C. B., \& Jaradat, R. M. (2014). System requirements engineering in complex situations. Requirements Engineering, 19(1), 45-62. doi:10.1007/s00766-012-0157-0

Keating, C. B., \& Katina, P. F. (2011). Systems of systems engineering: Prospects and challenges for the emerging field. International Journal of System of Systems Engineering, 2(2-3), 234-256. doi:10.1504/IJSSE.2011.040556

Keating, C. B., Padilla, J. J., \& Adams, K. (2008). System of systems engineering requirements: Challenges and guidelines. Engineering Management Journal, 20(4), 24-31. doi:10.1080/ 10429247.2008.11431785

Kerlinger, \& Lee, H. B. (2000). Foundations of behavioral research. Fort Worth, TX: Harcourt College Publishers.

Kordova, S. K., Ribnikov, G., \& Frank, M. (2015). Developing systems thinking among engineers: Recent study findings. In Systems Conference (SysCon), 2015 9th Annual IEEE International (pp. 50-53). Vancouver, BC: IEEE.

Lawrence, J. M., Hossain, N. U. I., Nagahi, M., \& Jaradat, R. (2019). Impact of a cloud-based applied supply chain network simulation tool on developing systems thinking skills of undergraduate students. In Proceedings of the International Conference on Industrial Engineering and Operations Management, Toronto, Canada, October 23-25.

Maier, M. W. (2005). Research challenges for systems-of-systems. In Systems, Man and Cybernetics, 2005 IEEE International Conference on Systems, Man, and Cybernetics (Vol. 4, pp. 3149-3154). Waikoloa, HI: IEEE.

Mitroff, I. (1997). Smart thinking for crazy times: The art of solving the right problems (pp. 3320-94111). San Francisco, CA: Berrett-Koehler Publishers, Inc.

Owens, W. A. (1996). The emerging US system-of-systems (No. 63). Washington, DC: National Defense Univ Washington DC Inst for National Strategic Studies.

Plate, R. (2008). Attracting institutional support through better assessment of systems thinking. The Creative Learning Exchange Newsletter, 17(3), 1-8.

Sauser, B., \& Boardman, J. (2008). Taking hold of system of systems management. Engineering Management Journal, 20 (4), 3-8. doi:10.1080/10429247.2008.11431782

Sekaran, U. (2003). Research methods for business: A skill building approach. New York, NY: John Wiley \& Sons.

Senge, P. (1990). The fifth discipline, the art and practice of the learning organization. New York, NY: Bantam Doubleday Dell Publishing Group.

Skyttner, L. (2001). General systems theory: Ideas \& applications. Hackensack, NJ: World Scientific.

Sweeney, L. B., \& Sterman, J. D. (2000). Bathtub dynamics: Initial results of a systems thinking inventory. System Dynamics Review, 16(4), 249-286. doi:10.1002/(ISSN) 1099-1727
Trochim, W. M., Cabrera, D. A., Milstein, B., Gallagher, R. S., \& Leischow, S. J. (2006). Practical challenges of systems thinking and modeling in public health. American Journal of Public Health, 96(3), 538-546. doi:10.2105/AJPH.2005.066001

Tseng, W. T., Dörnyei, Z., \& Schmitt, N. (2006). A new approach to assessing strategic learning: The case of selfregulation in vocabulary acquisition. Applied Linguistics, 27 (1), 78-102. doi:10.1093/applin/ami046

Von Bertalanffy, L. (1968). General system theory. New York, NY: George Braziller.

Whitehead, N. P., Scherer, W. T., \& Smith, M. C. (2015). Systems thinking about systems thinking a proposal for a common language. IEEE Systems Journal, 9(4), 1117-1128. doi:10.1109/JSYST.2014.2332494

Wilensky, H. L. (1967). Organizational intelligence. New York, NY: Basic Books.

Wright, D., \& Meadows, D. H. (2012). Thinking in systems: A primer. Vermont, VT: Green Publishing. 


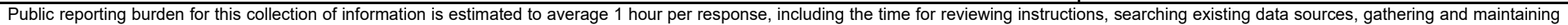

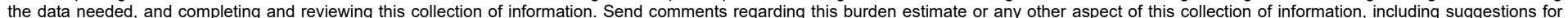

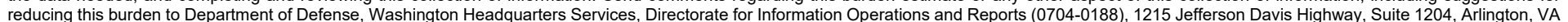

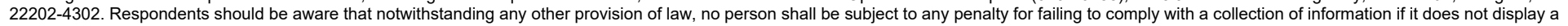
currently valid OMB control number. PLEASE DO NOT RETURN YOUR FORM TO THE ABOVE ADDRESS.
1. REPORT DATE (DD-MM-YYYY)
January 2021

4. TITLE AND SUBTITLE

Assessment of Workforce Systems Preferences/Skills Based on Employment Domain

\section{AUTHOR(S)}

Raed Jaradat, Erin Stirgus, Simon R. Goerger, Randy K. Buchanan, Niamat Ullah Ibne Hossain, Junfeng Ma, and Reuben Burch

\section{PERFORMING ORGANIZATION NAME(S) AND ADDRESS(ES)}

U.S. Army Engineer Research and Development Center

Information Technology Laboratory

3909 Halls Ferry Road

Vicksburg, MS 39180

9. SPONSORING / MONITORING AGENCY NAME(S) AND ADDRESS(ES)

US Army Corps of Engineers

Washington, DC 20314

\section{DATES COVERED (From - To)}

5a. CONTRACT NUMBER

5b. GRANT NUMBER

5c. PROGRAM ELEMENT NUMBER

0603461A

5d. PROJECT NUMBER

DW5

5e. TASK NUMBER

01

5f. WORK UNIT NUMBER

8. PERFORMING ORGANIZATION REPORT NUMBER

ERDC/ITL MP-21-1

10. SPONSOR/MONITOR'S ACRONYM(S)

11. SPONSOR/MONITOR'S REPORT NUMBER(S)

\section{DISTRIBUTION / AVAILABILITY STATEMENT}

Approved for public release; distribution is unlimited.

\section{SUPPLEMENTARY NOTES}

This paper was originally published online in the Engineering Management Journal 32(1) on November 8, 2019. Project funding was under Army RDTE.

DOI: $10.1080 / 10429247.2019 .1672407$.

\section{ABSTRACT}

Given the growing demand for a workforce with an understanding of system of systems, there is a need to assess an individual's systems thinking skills. This research was undertaken to address this need by measuring an individual's inclination to work on complex system problems based on their systems thinking score. This article investigates the correlation between employment domains and an individual's systems thinking preferences/skills. Results of this research show that each employment domain is significantly different in their systems thinking preferences/skills profiles as well as significantly different in how the employment domains perceive change and their system's worldview.

\section{SUBJECT TERMS}

Complex Systems, Systems Preferences/Skills, Employment Domains, Systems Thinking

\begin{tabular}{l} 
16. SECURITY CLASSIFICATION OF: \\
\hline \begin{tabular}{c|c|c|} 
a. REPORT & b. ABSTRACT & c. THIS PAGE \\
Unclassified & Unclassified & Unclassified \\
\hline
\end{tabular}
\end{tabular}

\begin{tabular}{c|c|}
$\begin{array}{c}\text { 17. LIMITATION } \\
\text { OF ABSTRACT }\end{array}$ & $\begin{array}{c}\text { 18. NUMBER } \\
\text { OF PAGES }\end{array}$ \\
SAR & 15 \\
\hline
\end{tabular}

19a. NAME OF RESPONSIBLE PERSON

19b. TELEPHONE NUMBER (include area code) 